\title{
A influência da obra de Alexander von Humboldt na geografia escolar do Ensino
}

\section{Médio}

\author{
The influence of Alexander von Humboldt's work in the school geography discipline of High School \\ La influencia del trabajo de Alexander von Humboldt en la geografía de la escuela secundaria
}

Recebido: 25/05/2021 | Revisado: 01/06/2021 | Aceito: 01/06/2021 | Publicado: 15/06/2021

\author{
Malena Silva Nunes \\ ORCID: https://orcid.org/0000-0002-2868-1376 \\ Centro Federal de Educação Tecnológica de Minas Gerais, Brasil \\ E-mail: malenanunes@cefetmg.br \\ Matusalém de Brito Duarte \\ ORCID: https://orcid.org/0000-0003-0576-7481 \\ Centro Federal de Educação Tecnológica de Minas Gerais, Brasil \\ E-mail: matusalem@cefetmg.br \\ Kalebe de Paula Souza Cruz \\ ORCID: https://orcid.org/0000-0002-3515-3563 \\ Centro Federal de Educação Tecnológica de Minas Gerais, Brasil \\ E-mail: kalebedepaulasouzacruz@gmail.com
}

\begin{abstract}
Resumo
Ainda que vários conteúdos abordados na geografia da Educação Básica tenham sido tratados, pioneiramente, por Alexander von Humboldt, seu nome e sua imagem poderiam estar mais presentes neste nível de ensino. Esse trabalho apresenta os resultados de uma pesquisa que objetivou identificar aspectos da obra de Humboldt que se tornaram relevantes para a ciência geográfica e entender de que maneira é possível associar/transpor a geografia acadêmica à geografia escolar. A pesquisa, do tipo documental, analisou a obra "A invenção da natureza - a vida e as descobertas de Alexander Von Humboldt", lida e discutida em reuniões remotas. A partir das análises foram elencadas as principais descobertas de Humboldt a partir de quatro eixos temáticos: meio ambiente, sociedade e cultura, política e curiosidades. Como exemplos, podemos apontar a definição das isotermas, a descoberta do equador magnético, os estudos sobre a dinâmica de formação de minerais, a relação direta entre a ação humana, por meio do desmatamento, e as mudanças climáticas, além da atuação em outras áreas, no âmbito social e político. Diante dos feitos de Humboldt, buscou-se relacionar tais descobertas com os conteúdos abordados no programa de Geografia no Ensino Médio do CEFET-MG. Assim, foi possível apontar possibilidades para inserir Humboldt, e seus estudos, na geografia escolar da Educação Básica.
\end{abstract}

Palavras-chave: Alexander Von Humboldt; Geografia escolar; Educação básica.

\begin{abstract}
Although several ceossiste covered in the geography of Basic Education have been pioneered by Alexander von Humboldt, his name and image could be more present at this level of education. This work presents the results of a research that aimed to identify aspects of Humboldt's work that became relevant to geographic Science and to understand how it is possible to associate / transpose academic geography with school geography. The research, of the documentar type, analyzed the work "The invention of nature - the life and discoveries of Alexander von Humboldt", read and discussed in remote meetings. From the analyzes, Humboldt's main discoveries were listed based on four thematic axes: environment, society and culture, politics and curiosities. As examples, we can point to the definition of isotherms, the discovery of the magnetic equator, studies on the dynamics of mineral formation, the direct relationship between human action, through deforestation, and climate change, in addition to acting in other areas, in the social and political spheres. In view of Humboldt's achievements, we sought to relate these discoveries to the contents covered in the CEFET-MG's Geography in High School program. Thus, it was possible to point out possibilities for inserting Humboldt, and his studies, into the school geography of Basic Education.
\end{abstract}

Keywords: Alexander Von Humboldt; School geography; Basic education.

\section{Resumen}

Aunque varios contenidos cubiertos em la geografía de la Educación Básica han sido pioneiros em los estudios de Alexander von Humboldt, su nombre e imagen podrían estar más presentes em este nivel educativo. Este trabajo presenta los resultados de em investigación que tuvo como objetivo identificar aspectos del trabajo de Humboldt que se volvieron relevantes para la ciência geografía y compreender cómo es posible asociar / transponer la geografía académica em la geografía escolar. La investigación, de tipo documental, analizó la obra "La invención de la 
naturaliza - la vida y los descubrimientos de Alexander von Humboldt", leída y discutida em encuentros remotos. A partir de los análisis, se enumeraron los principales descubrimientos de Humboldt em base a cuatro ejes temáticos: medio ambiente, sociedad y cultura, política y curiosidades. Como ejemplos, podemos señalar la definición de isotermas, el descubrimiento del ecuador magnético, los estudios sobre la dinámica de formación de minerales, la relación directa entre la acción humana, a través de la deforestación, y el cambio climático, además de actuar em otras áreas, em las esferas social y política. Em vista de los logros de Humboldt, buscamos relacionar estos descubrimientos em los contenidos cubiertos en el programa de Geografía em la escuela secundaria CEFET-MG. Así, fue posible señalar posibilidades de inserción de Humboldt, y sus estudios, em la geografía escolar de la Educación Básica.

Palabras clave: Alexander Von Humboldt; Geografía escolar; Educación básica.

\section{Introdução}

A maneira com que a ciência geográfica evoluiu ao longo do tempo é tema de estudo de diferentes trabalhos, conforme Amorim Filho (1999) e Claval (2002). Alguns pensadores foram fundamentais para a consolidação da Geografia tal qual a estudamos na atualidade, destacando Heródoto, Eratóstenes, Estrabão, Cláudio Ptolomeu, Immannuel Kant, Alexander von Humboldt e Karl Ritter. Os dois últimos são considerados fundadores da Geografia enquanto ciência, tendo em vista que sistematizaram seus fundamentos teórico-metodológicos. Em 1.825, na Alemanha, foi criado o primeiro curso acadêmico de Geografia, a partir de então, destacam-se as contribuições de Friedrich Ratzel, Paul Vidal de la Blache, Yves Lacoste e, no Brasil, Milton Santos (Sene \& Moreira, 2016).

Este trabalho, fruto de um projeto de Iniciação Científica Voluntária Júnior realizado no Centro Federal de Educação Tecnológica de Minas Gerais (CEFET-MG), se concentra nas contribuições de Alexander von Humboldt, que nasceu e faleceu em Berlim, em 1.769 e 1.859, respectivamente. Vindo de uma família aristocrática prussiana, se formou em Economia Política, Matemática, Ciências Naturais, Botânica, Física e Mineralogia. Ao longo da vida, fez diversas viagens, tendo sido a mais marcante, com duração de quatro anos, rumo ao continente americano, o que incluiu excursões pelo rio Amazonas. Dantas \& Medeiros (2008) salientam, dentre os feitos de Humboldt, o interesse pela diferenciação espacial, considerando que a paisagem resulta da interação de vários fenômenos; a comparação entre formações vegetais de regiões distintas, como a América Latina e a Sibéria; a busca por semelhanças entre as culturas dos povos asiáticos e dos índios americanos; investigações em escalas em diferentes níveis (mundial, continental e regional), resultando em uma sistematização do conhecimento geográfico.

Ferreira \& Simões (1986) destacam que Humboldt era um cientista naturalista preocupado com questões da botânica, física, química, geologia e, até mesmo astronomia, sendo a geografia um conhecimento utilizado basicamente para a localização absoluta dos lugares. Para elas, Humboldt na verdade tinha como objetivo construir uma ciência integradora, partindo da Terra como um todo orgânico com fenômenos interdependentes (Ferreira \& Silva, 1986).

Ao analisarmos a vida e obra de Humboldt, percebemos como esse pesquisador sempre esteve à frente do seu tempo, problematizando, numa época dominada pelo cartesianismo e pela fragmentação da ciência, a questão da interdependência dos fenômenos geográficos, fato que o levou a ser reverenciado na ciência geográfica, que se sistematizou enquanto ciência de síntese. Fazendo uma leitura retrospectiva das contribuições de Humboldt, percebemos também, uma similaridade com a Teoria Geral dos Sistemas, criada pelo biólogo Ludwig von Bertalanffy, em 1968, que tinha como objetivo o estudo não apenas das partes, de forma disciplinar, mas buscar a resolução dos problemas nas interações e dinâmicas dos elementos da natureza, base para a construção de uma geografia da complexidade. Assim como é possível, também, uma relação para com os geossistemas, que derivam da Teoria Geral dos Sistemas e abordados pioneiramente por Sotchava e Bertrand, na década de 1960. A análise geossistêmica envolveria, portanto, fatores biogeográficos e socioeconômicos. (Camargo, 2005; Nascimento \& Sampaio, 2004).

A partir do campo da História Ambiental e seu olhar sobre as questões ambientais, Martins (2008) aponta como o interesse nos estudos da relação entre sociedade e natureza se tornaram problema de pesquisa tardiamente, somente a partir dos 
anos 1970, coincidindo inclusive com as discussões internacionais sobre a temática meio ambiente (Barbosa \& Barsand, 2012). Humboldt, porém, em uma época em que se acreditava na natureza enquanto recurso inesgotável e subjugada ao homem, já demonstrava preocupação com os impactos ambientais do uso da natureza, descrevendo os processos de integração entre elementos da natureza inclusive em escalas diferenciadas, como na relação entre desmatamento e recarga de nascentes.

Martins (2008) apresenta três lições de que os estudos de História Ambiental têm contribuído para se pensar o meio ambiente, mediante a crise estrutural que vivemos, sendo elas: a necessidade de abordar o ambiente sob a perspectiva da totalidade; a importância de apreender a diversidade histórica das interrelações natureza-sociedade e, por fim, a necessidade de desdenhar o sonho prometeico do domínio do universo pelo homem (Martins, 2008). Mais uma vez, a vida e obra de Humboldt se apresenta como importante documentação histórica que corroboram e colaboram com essas três lições, numa época em que não havia pretensão sequer de fazer uma análise ambiental, mas sim, desenvolver uma ciência de categorização e descrição de elementos e fatos.

Nesse sentido é que Humboldt, a partir da obra de Wulf (2016), se apresenta como um importante personagem da história ambiental, bem como dos estudos da Geografia e análise ambiental, dialogando com pensadores importantes da contemporaneidade, como Leff (2006), que acredita na interdisciplinaridade como caminho para se construir um saber ambiental que problematize diversas esferas de sua constituição. Humboldt, apesar de não sistematizar críticas políticas, é apresentado por Wulf (2016) como um sujeito que também questionava as instâncias de poder político e produtivo (questões como a escravidão nas Américas; a exploração das terras tropicais, etc). O viajante expressava sua insatisfação e sua percepção dos meandros políticos de poder que atravessavam os caminhos por onde passou, mas por não encontrar interlocutores para ampliar o debate, não pôde avançar na produção de uma epistemologia política do meio ambiente. Ao observar pelo retrovisor histórico podemos concluir que Humboldt tinha um olhar para além de um viajante naturalista, podendo ser considerado um cientista da grande área das ciências humanas e sociais aplicadas.

Mesmo antes da publicação da obra de Wulf (2016), a importância de Humboldt é, portanto, nítida e reconhecida no meio acadêmico, onde sua obra é bastante estudada e debatida, o que não ocorre, na mesma medida, no ambiente escolar. Ou seja, ainda que vários conteúdos abordados na geografia da Educação Básica tenham sido tratados, pioneiramente, por Humboldt, seu nome e sua imagem poderiam estar mais presentes neste nível de ensino. Destaca-se que o ensino da geografia escolar se dá, basicamente, por meio do livro didático, onde, segundo Callai (2011), ainda que estejam presentes vários dados e informações, é necessário transformá-los em conhecimento.

De acordo com Cavalcanti (2012), os conteúdos abordados nas disciplinas escolares são responsáveis por definir a especificidade de cada uma delas, diferenciando-as e caracterizando-as de acordo com seus objetos de estudo. Especificamente sobre a Geografia, a autora destaca que cabe a ela "apresentar aspectos naturais e sociais (associados, inter-relacionados, como se indica atualmente) de diferentes lugares do mundo, 'agrupados' de diferentes formas, por regiões, por continentes, para que sejam aprendidos pelos alunos." (Cavalcanti, 2012, p.134). Assim, considerando a compreensão da espacialidade como objeto de análise geográfica, Callai (2011) destaca que, através da educação geográfica, se trabalharia com a ideia de aprendizagens significativas. A Geografia é, portanto, mais do que uma sequência de ilustrações. Hartshorne (1978) apud Neto (2008) aponta que a Geografia estuda as interrelações entre fenômenos heterogêneos, sob uma visão sintética, e Limberger (2006) acrescenta que são necessárias diferentes escalas integradas para se analisar o homem que interage e vive no espaço geográfico.

Serão apresentados, neste trabalho, os resultados obtidos a partir da análise da importância dos estudos e das descobertas de Alexander von Humboldt, evidenciando aquelas que se fazem presentes em conteúdos geográficos do cotidiano escolar da disciplina de Geografia no Ensino Médio. Para tanto, recorreu-se a uma pesquisa documental, por meio da leitura do livro “A invenção da natureza - a vida e as descobertas de Alexander Von Humboldt” (Wulf, 2016), onde buscou-se identificar aspectos da obra de Humboldt que se tornaram relevantes para a ciência geográfica. Também pretende-se entender de que 
maneira é possível associar / transpor a geografia acadêmica à geografia escolar a partir da associação entre os conteúdos das obras de Humboldt e aqueles presentes na disciplina de Geografia no Ensino Médio do CEFET-MG.

\section{Metodologia}

Para que os objetivos fossem alcançados, a pesquisa foi composta pelas seguintes etapas: levantamento bibliográfico acerca da evolução do pensamento geográfico e contextualização histórica e social da época estudada; leitura de uma obra que abarca a trajetória de Humboldt, identificando os aspectos mais relevantes do ponto de vista geográfico e científico como um todo, enfatizando as possibilidades de aplicação da geografia acadêmica ao ambiente escolar; levantamento dos conteúdos programáticos e do currículo de geografia do CEFET-MG.

Portanto, a partir de uma obra específica foram extraídas as principais informações que serão apresentadas e discutidas adiante. Destaca-se que, conforme aponta Oliveira (2007),

A pesquisa documental é muito próxima da pesquisa bibliográfica. $\mathrm{O}$ elemento diferenciador está na natureza das fontes: a pesquisa bibliográfica remete para as contribuições de diferentes autores sobre o tema, atentando para as fontes secundárias, enquanto a pesquisa documental recorre a materiais que ainda não receberam tratamento analítico, ou seja, as fontes primárias. Essa é a principal diferença entre a pesquisa documental e pesquisa bibliográfica. No entanto, chamamos a atenção para o fato de que: na pesquisa documental, o trabalho do pesquisador (a) requer uma análise mais cuidadosa, visto que os documentos não passaram antes por nenhum tratamento científico. (Oliveira, 2007, p.70).

A obra aqui analisada narra acontecimentos da vida de Humboldt de forma minuciosa e apresenta, de maneira bastante descritiva, as viagens e descobertas feitas por ele. Salienta-se que a obra se baseia nas publicações de Humboldt, incluindo as cartas trocadas durante sua vida. O livro possui 587 páginas, sendo dividido em cinco partes. Ao longo da leitura foi feito fichamento das principais ideias e elaborada uma síntese das principais descobertas nos vários âmbitos tratados. A partir do levantamento das principais descobertas, os programas de Geografia do $1^{\circ}$ e do $2^{\circ}$ ano do Ensino Médio do CEFETMG foram analisados, com o intuito de identificar quais conteúdos estudados na Instituição foram, também, abordados por Humboldt ao longo da vida.

\section{O Contexto de Vivência de Humboldt}

O contexto vivido por Humboldt foi de suma importância para a criação e realização de suas descobertas, assim como para a construção e execução de suas teorias. Entender não somente o seu momento familiar, como a própria vida no continente europeu, permite demonstrar porque Humboldt alcançou feitos tão importantes nas mais variadas áreas da ciência. Nascido no século XVIII em Berlim e proveniente de uma família abastada e aristocrata, nunca passou por dificuldades financeiras na infância, pelo contrário, sempre esteve cercado da melhor educação possível. Desde criança, ele e seu irmão foram tutelados por receptores particulares que eram encabidos dos melhores ensinamentos e dos ideais iluministas fomentados na época. Humboldt, porém, demonstrou sua personalidade cedo, pois já na infância era ávido pela natureza e as instigações que ela trazia. Segundo Wulf (2016, p. 39) ele "preferia escapar da sala de aula toda vez que podia a fim de vaguear pela região campestre, coletando e desenhando plantas, animais e pedras". Ainda assim, teve atritos diretos com a mãe, que não aceitava a forma como ele se portava, além de ser conservadora e defender a educação concreta, baseada na leitura e no estudo. Assim, almejava que Humboldt fosse como o irmão, que passava horas dentro de uma sala lendo e apreendendo sobre linguagens e história.

Além do contexto familiar, o contexto histórico é essencial para entender a formação dos pensamentos de Humboldt, já que o século XVIII foi marcado por eventos importantes e pela presença de pessoas que contribuíram diretamente para a ciência. Um dos principais panoramas vividos neste século foi o aumento considerável da exploração marítima. Isso ocorreu 
devido ao desenvolvimento da tecnologia empregada nos barcos, além do surgimento dos grandes barcos a vela, ou seja, uma combinação entre força e velocidade tornou as viagens oceânicas mais dinâmicas e vantajosas. Juntamente aos avanços marítimos ocorreram, também, avanços cartográficos. A precisão das medições e a quantidade delas aumentaram significativamente, gerando uma intensa e incansável busca pela evolução e expansão territorial. Assim, os primeiros passos para a globalização estavam sendo dados. Outro evento significativo neste mesmo momento foi a Revolução Industrial, iniciada na Inglaterra em 1760. Houve uma revolução profunda nas técnicas produtivas e na forma como o homem manipulava e transformava a natureza. Tal revolução foi essencial para destacar o continente o europeu, fazendo com que o centro produtivo e científico do mundo girasse em torno da Europa. Isso gerou intensa migração da comunidade cientifica em busca de evolução tecnológica e aprendizado.

Aliada à Revolução Industrial, esse período foi marcado pela ascensão de um novo panorama científico mundial. Com o aumento das navegações e a expansão territorial houve também um aumento expressivo de cientistas e informações circulando entre os continentes. Dessa forma, é possível afirmar que o compartilhamento de ideias e as complementações científicas foram o ponto chave desse período. Descobertas como a lei da gravitação universal de Newton e o sistema heliocêntrico de Copérnico, acabaram com a certeza da Terra como centro do universo e foram essenciais para mudar a dinâmica científica do século em questão e dos séculos seguintes. Segundo Dantas \& Medeiros (2008),

O século XIX, do ponto de vista do desenvolvimento da ciência é especialmente importante para a sistematização e institucionalização da Geografia. É no final do século XVIII e início do XIX que se instala um novo sistema de positividades, apoiando nas observações dos fatos, sobretudo a partir dos estudos da Física por parte de Newton. Para Newton o conhecimento deve resultar da observação, do cálculo e da comparação dos resultados, o que permitiria a elaboração de leis. (Dantas \& Medeiros, 2008, p.4).

Conclui-se, portanto, que o contexto geográfico e científico vivido no século XVIII foi o berço para a preparação de Humboldt. Diversos fatores presenciados de forma contemporânea a ele ajudaram diretamente na formação do seu pensamento crítico e científico, influenciando na formação de um dos maiores naturalistas de todos os tempos.

As amizades e os relacionamentos construídos por Humboldt também são fundamentais quando se considera as relações de influência (influenciador e influenciável) estabelecidas ao longo de sua vida. Considera-se que a amizade e os relacionamentos vividos são essenciais na formação do ser e, assim, também na forma como ele pensa e expõe suas ideias, conforme abordado por Borsa (2013):

A amizade é reconhecida na literatura científica como uma importante fonte de felicidade e de bem-estar subjetivo, uma vez que proporciona o suporte social, o compartilhamento de experiências, de interesses, de sentimentos e de emoções (Cheng, \& Furnham, 2002; Hartup, 1996). As relações de amizade permitem ao indivíduo o aprendizado de habilidades sociais importantes para o estabelecimento de relações interpessoais satisfatórias e harmoniosas ao longo de todo o ciclo vital. Entende-se a amizade como uma interação íntima, espontânea e recíproca entre duas pessoas, caracterizada por um forte componente afetivo (Bukowski et al, 1996). (Borsa, 2013, p. 161).

Com Humboldt não foi diferente. Seus relacionamentos e inspirações pessoais foram essenciais para criar sua personalidade e o seu próprio estilo como naturalista e cientista. Durante toda a vida, nas viagens, palestras e reuniões teve contato com inúmeras pessoas de relevância no mundo acadêmico. Em seus encontros, Humboldt prezava pela troca de informações e buscava analisar e entender as teorias apresentadas a ele. A Figura 1 apresenta, de forma esquemática, as principais personalidades que viveram e tiveram contato com Humboldt. 
Figura 1. Influências e amizades de Humboldt.

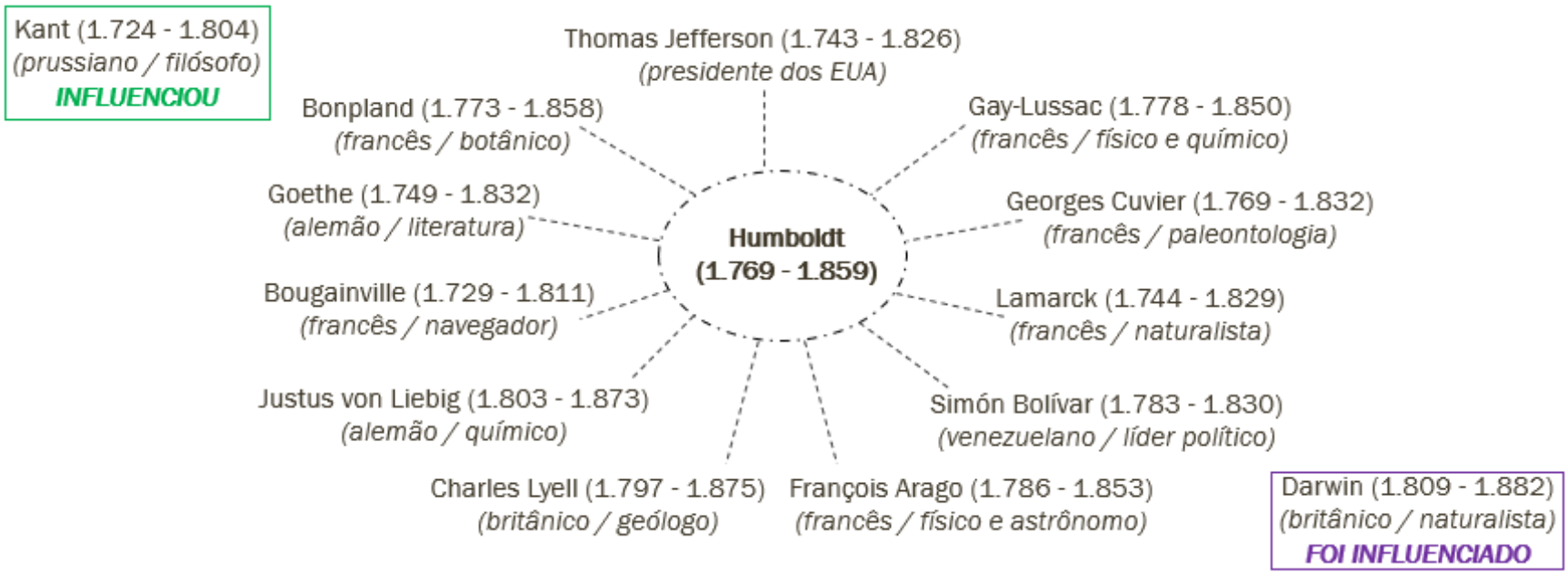

Fonte: Autores.

Destaca-se, dentre os contatos que Humboldt teve ao longo da vida, Kant, um dos maiores nomes da filosofia, que foi responsável por influenciar diretamente o pensamento Humboldtiano de sistematização da natureza, teoria essa que mais a frente viria a ser um dos estudos mais importantes de sua vida. Como apontado por Wulf (2016),

Ao longo de quarenta anos, Kant ministrou por 48 vezes essa série de conferências, sob o título Physische GeographieI, na qual insistia que o conhecimento era um construto sistemático em que os fatos individuais precisavam caber e adequar-se num arcabouço mais amplo de modo a fazer sentido. Ele usava a imagem de uma casa para explicar o seguinte: antes de construí-la, tijolo por tijolo e pedaço por pedaço, era necessário ter uma ideia de qual seria o aspecto do prédio inteiro. Foi esse conceito de sistema que se tornou a peça-chave do pensamento posterior de Humboldt. (Wulf, 2016, p.66).

Outra personalidade importante foi Charles Darwin, contemporâneo a Humboldt, porém mais novo. Foi um dos mais famosos naturalistas da história e baseou grande parte de seus estudos iniciais nas obras de Humboldt. Durante suas viagens e pesquisas, Darwin adotou teorias e métodos postulados por Humboldt. A influência, quase idolatria, era tão marcante que Darwin chegou a escrever com caraterísticas iguais às de Humboldt em seus diários de pesquisa, conforme destacado por Wulf (2016).

\section{Principais Descobertas}

Apesar de ter afinidade por algumas áreas da ciência como geologia e botânica, Humboldt não se prendeu somente a elas. Ele trabalhou em diversas áreas científicas e contribuiu de forma relevante a todas elas, o que se tornou um grande diferencial para a época (e ainda hoje). Dessa forma, ao analisar de forma minuciosa a obra, foram percebidas diversas áreas de atuação. Assim, as descobertas de Humboldt foram separadas em cinco áreas, sendo elas: Meio ambiente, Sociedade e Cultura, Política, Curiosidades e Obras Publicadas.

A área de maior domínio de Humboldt foi a área ambiental. Ainda criança ele demonstrava sua aptidão ao ficar horas nos bosques de sua casa em Berlim, enchendo seus bolsos de insetos e minerais. Como uma forma de escapar do academicismo imposto pela família se tornou inspetor de minas aos 20 anos e começou a ter contato diretos com o solo e os minerais.

Um ponto importante desenvolvido por Humboldt foram as análises em campo. Apesar de escrever e publicar obras, a maior parte de sua vida foi prática. Ele misturava a escrita com o campo, sempre levando diários e cadernetas de anotações 
para desenhar e escrever tudo que achava relevante. Em sua primeira grande viagem à América, Humboldt teve enfrentou diversos problemas. Na Venezuela, as margens do Lago Valência, em contato com nativos, descobriu que o lago estava perdendo significativamente seu porte hídrico e apontou que a causa seria o desmatamento da mata ciliar aliada a transposição dos cursos d'água para irrigação, sendo o primeiro cientista a apontar e entender a relação entre corpos hídricos e mata ciliar.

Humboldt passou meses na Floresta Amazônica, coletando e catalogando espécies de plantas e insetos. Nesse período, fez uma caravana pelos rios, o que o possibilitou ser o primeiro cientista a desenhar e catalogar detalhadamente os sistemas fluviais amazônicos. Através do mapa de Humboldt diversos cientistas tiveram acesso aos rios amazônicos no século XVIII.

Nesse período Humboldt também compreende e pontua, ao escalar o monte Chimborazo, a relação de interligação natural, já alimentada por Kant. Humboldt entendeu e publicou as relações entre clima, relevo e temperatura, e como esses fatores interagiam diretamente no solo e na vegetação. Essa teoria foi essencial para a consolidação da geografia enquanto matéria e disciplina acadêmica e escolar.

Sua segunda grande viagem foi para a Rússia, já no final de sua vida. Humboldt, diante da oportunidade de viajar para a parte oriental da Europa, observou que poderia comparar os resultados obtidos na América com os obtidos na Rússia a fim de encontrar padrões e explicações para seus pensamentos na época. As margens do rio Volga, Humboldt entendeu o fenômeno de aumento e diminuição dos níveis de água e os explicou pela primeira vez. Aqui, os relacionou aos movimentos das placas tectônicas e dos continentes, também observados quando visitou vulcões na América. As explicações de Humboldt contribuiriam para a criação da teoria da Deriva Continental quase 100 anos mais tarde.

Por fim, através de medições de temperaturas por todo o planeta, o que incluiu a ajuda de diversos cientistas, Humboldt criou as isotermas, produzindo um mapa de isotermas. As linhas de igual temperatura foram essenciais para diversos estudos geográficos futuros e para entender as análises de clima e as mudanças climáticas no planeta, estudadas ainda hoje.

Humboldt sempre teve ideias a frente de sua época, sendo que uma das características que marcou sua vida foi a empatia pelo próximo. Durante o período de viagens pela América vivenciou e analisou o sistema colonial e a escravidão de índios e negros, criticando severamente em suas cartas e livros esse sistema. Apesar da época, Humboldt defendia cientificamente que nenhum ser humano era inferior ao outro, todos eram dotados do mesmo vigor, dotes físicos e mentais e, por isso, para ele a escravização não fazia sentido e deveria ser extinta (Wulf, 2016). Além disso, Humboldt entendia o homem como o principal destruidor da natureza, tendo sido um dos primeiros cientistas a compreender o conceito de uso sustentável e a importância dos recursos naturais. Criticou os avanços da modernidade, tendo em vista que o pensamento da época era contrário à preservação ambiental e favorável ao sistema colonial de exploração.

Humboldt foi, ainda, responsável por movimentos políticos significativos em sua época. Em período de estadia na França, conheceu e se tornou amigo íntimo de Simón Bolívar, na época um jovem cientista com ideais revolucionários. Durante anos Humboldt o instruiu e o apresentou seus pensamentos críticos sobre a América, os problemas com o colonialismo e a escravidão, o que levou Simón a alimentar chamas revolucionarias já existentes nele. Além da influência pessoal, Simón também baseou todo o seu conhecimento naturalista e territorial nas obras de Humboldt sobre a América, assim tendo os livros como base para aplicação de suas ideias. Como apresentado por Wulf (2016),

Os livros e ideias de Humboldt fomentariam a libertação da América Latina - da sua crítica ao colonialismo e à escravidão ao retrato das majestosas paisagens. Em 1809, dois anos após sua primeira publicação na Alemanha, o Ensaio sobre a geografia das plantas foi traduzido para o espanhol e publicado em um periódico científico fundado em Bogotá por Francisco José de Caldas, um dos cientistas que Humboldt conhecera durante sua expedição nos Andes. Bolívar disse mais tarde que, "Com sua pena", Humboldt havia despertado a América do Sul e ilustrado por que os sul-americanos tinham inúmeras razões para sentir orgulho de seu continente. Até hoje o nome de Humboldt é muito mais conhecido na América Latina do que na maior parte da Europa e dos Estados Unidos. (Wulf, 2016, p.218). 
O segundo contato entre Humboldt e a política se deu em seu período de viagens pelo Estados Unidos, quando se encontrou e hospedou na casa de Thomas Jefferson, a convite do próprio, que era um grande admirador de seu trabalho. Humboldt e Thomas Jefferson compartilharam ideias sobre botânica, agronomia, biologia e filosofia. De forma inconsciente Humboldt foi responsável por descrever e fazer mapas de grande parte do norte do território americano. Informações como características do solo e da vegetação foram fundamentais para Jefferson comandar o avanço do crescimento dos EUA em direção ao norte. Além disso, outro grande interesse era a fronteira entre EUA e México, já que Humboldt também fez descrições detalhadas dessa região a Jefferson.

Além das descobertas científicas, Humboldt foi responsável por diversas atribuições que se perpetuam até os dias de hoje. Durante sua viagem pela América, catalogou e enviou espécies de plantas para a Europa, de maneira que diversas especiarias americanas foram introduzidas naquele continente (como a Castanha-do-pará). Também tornou conhecida e fomentou a utilização de instrumentos em campo. A instrumentalização para medições in loco se perpetua até os dias atuais. Humboldt fez medições em alturas nunca antes alcançadas, tendo se tornado, na época, o primeiro cientista a fazer medições acima dos 3 mil metros de altitude. Humboldt também colocou o método da sistematização em prática, moldando seus pensamentos e estudos na interligação da natureza. Atualmente a comunidade cientifica como um todo entende a natureza como um sistema de conexões, porém Humboldt deu início a esse entendimento séculos atrás.

Um fator que tornou Humboldt conhecido mundialmente em um século ainda pouco globalizado foram suas obras publicadas e suas cartas. Por meio de sua forma de escrever Humboldt revolucionou a ciência descritiva, transpondo de forma detalhada o que via em suas viagens para o papel e mostrando ao mundo a beleza das paisagens. Estima-se que em toda sua vida Humboldt escreveu cerca de 33 mil cartas e recebeu mais de $100 \mathrm{mil}^{1}$. Humboldt publicou mais de 15 obras escritas com diversos volumes e extensões sobre suas viagens, sendo obras descritivas e informativas, além de revolucionar a forma da escrita naturalista.

Quadros da Natureza foi escrito em 1804 quando Humboldt passava por um momento de profunda tristeza após chegar de suas viagens na América. Essa obra se tornou a mais famosa dele, com grande repercussão na época. Como destacado por Wulf (2016),

Este seria um dos livros de autoria de Humboldt de maior repercussão, um sucesso de vendas lido por muitos, e que por fim viria a ser publicado em sete línguas. Com Quadros da natureza, Humboldt criou um gênero completamente novo - um livro que combinava prosa vigorosa e abundantes descrições de paisagens com observações científicas, inaugurando o modelo para a maior parte dos textos atuais sobre a natureza. De todos os livros que Humboldt escreveu, este foi o seu favorito. (Wulf, 2016, p.198).

Com Quadros da Natureza, Humboldt descreveu os aspectos mais profundos presenciados por ele nas Américas, desde cumes andinos até o ataque de enguias elétricas. Sua escrita, quase poética, evidenciou as belezas e as diversidades do continente americano para o mundo.

Outra obra importante foi Essai sur la géographie des plantes ("Ensaio sobre a geografia das plantas"), publicada em 1805 por Humboldt em conjunto com seu grande amigo Aimé Bonpland. Pela primeira vez a estrutura das plantas era tratada, de forma a ser considerada uma das primeiras obras de geobotânica, um assunto pouco difundido na época. A obra também ficou famosa por conter a figura Naturgemälde, um desenho de $90 \mathrm{~cm} \times 60 \mathrm{~cm}$ em que se relacionava vegetação e altitude a partir das observações feitas ao longo da escalada no monte Chimborazo, durante a visita ao Equador. Essa ilustração, assim

\footnotetext{
${ }^{1}$ As cartas escritas e recebidas por Humboldt foram parte dos documentos consultados por Andrea Wulf para se basear e escrever a obra analisada nessa pesquisa.
} 
como a obra, ficaram conhecidas mundialmente e foram replicadas por todo o mundo, sendo utilizada até os dias de hoje, especialmente em livros de geografia.

Uma das obras mais conhecidas é Kosmos, publicada entre 1845 e 1862 . A obra era composta por cinco volumes e se baseava nas palestras proferidas na Universidade de Berlim, além de fazer uma síntese geral dos conhecimentos adquiridos durante seus 40 anos de viagens. Nela, Humboldt explicava sua ideia de sistematização e interligação da natureza, apresentando sua teoria de conexão entre clima, vegetação e altitude já mostrada também em sua outra obra Naturgemälde.

\section{Humboldt e a Geografia no CEFET-MG}

O CEFET-MG conta, atualmente, com dois projetos de conteúdos programáticos, sendo um para o $1^{\circ}$ ano e outro para o $2^{\circ}$ ano, visto que na Instituição não há oferta da disciplina de Geografia no $3^{\circ}$ ano. Cada um deles é dividido em quatro unidades a serem desenvolvidas ao longo do ano letivo. Dessa forma, cada programa foi analisado de maneira a identificar possibilidades para a aplicação dos conhecimentos advindo das descobertas e vivências de Humboldt.

Quando se analisa o programa do $1^{\circ}$ ano (Quadro 1), nota-se a presença de conteúdos relacionados à Humboldt nas quatro unidades. A unidade 1, denominada "Introdução à geografia" apresenta evidentes ligações no que diz respeito à sistematização da geografia. A evolução do pensamento geográfico aconteceu por meio de diversos naturalistas durante os séculos, e dentre eles Humboldt foi essencial. Com sua ideia de conexão natural, demonstrou, por meio de livros e figuras a conexão entre natureza, clima e altitude, dando bases a teoria da natureza como uma união de fatores. Essa teoria se tornou o pilar fundamental para a construção da geografia enquanto ciência e disciplina escolar.

Quadro 1. Conteúdo Programático de Geografia do $1^{\circ}$ ano do CEFET-MG.

\begin{tabular}{|c|c|}
\hline \multicolumn{2}{|r|}{ Conteúdo Programático $-1^{\circ}$ ano } \\
\hline \multicolumn{2}{|r|}{$1^{\circ}$ Bimestre } \\
\hline Unidade 1 & $\begin{array}{l}\text { Introdução à Geografia } \\
\text { 1.1- Síntese da evolução do pensamento geográfico }\end{array}$ \\
\hline Unidade 2 & $\begin{array}{l}\text { Cartografia } \\
\text { 2.1 - Evolução da cartografia: da cartografia histórica às geotecnologias. } \\
\text { 2.2 - Forma e movimentos da Terra. } \\
\text { 2.3- Elementos do mapa (título, escala, legenda, coordenadas, orientação e fonte). } \\
\text { 2.4 - Fusos horários (teóricos; práticos; horário de verão; LID) } \\
\text { 2.5 - Representação e interpretação de documentos cartográficos (projeções cartográficas; } \\
\text { usos ideológicos da cartografia; geomarketing). }\end{array}$ \\
\hline \multicolumn{2}{|r|}{$\mathbf{2}^{\circ}$ Bimestre } \\
\hline Unidade 3 & $\begin{array}{l}\text { Geologia e geomorfologia } \\
\text { 3.1 - Teorias da origem da Terra (História geológica). } \\
\text { 3.2 - Estrutura interna da Terra, ciclo das rochas e estrutura geológica geral e do Brasil. } \\
\text { 3.3 - Deriva continental e tectônica de placas. } \\
\text { 4.1 - Agentes formadores e modeladores do relevo. } \\
\text { 4.2 - Macroformas do relevo continental e submarino. } \\
\text { 5.1 - Formação, degradação e conservação dos solos (intemperismo e erosão). }\end{array}$ \\
\hline Unidade 4 & $\begin{array}{l}\qquad \mathbf{3}^{\mathbf{0}} \text { Bimestre } \\
\text { Climatologia, domínios morfoclimáticos e meio ambiente } \\
\text { 6.1 - Elementos e fatores climáticos. } \\
\text { 6.2 - Tipos climáticos (climogramas; tipos de chuva). } \\
\text { 6.3 - Fenômenos climáticos (inversão térmica; ilha de calor; chuva ácida; efeito estufa) e } \\
\text { mudanças climáticas. } \\
\text { 7.1 - Vegetação e domínios morfoclimáticos. } \\
\text { 7.2 - As unidades de conservação. }\end{array}$ \\
\hline
\end{tabular}




\begin{tabular}{|c|c|}
\hline \multicolumn{2}{|r|}{$4^{\circ}$ Bimestre } \\
\hline Unidade 5 & $\begin{array}{l}\text { Recursos hídricos e energéticos } \\
\text { 8.1 - Ciclo hidrológico e ação antrópica (águas superficiais e subterrâneas). } \\
\text { 8.2 - Apropriação dos recursos hídricos e a água virtual (reuso da água; escassez hídrica). } \\
\text { 8.3 - Características dos rios e as bacias hidrográficas brasileiras. } \\
\text { 9.1 - Tipos e fontes de energia. } \\
\text { 9.2 - Matriz energética do Brasil e Mundial }\end{array}$ \\
\hline
\end{tabular}

Fonte: Autores.

A unidade 2, "Cartografia", possui um tópico sobre a evolução da cartografia e a cartografia histórica, o que também representa aspectos importantes apontados e desenvolvidos por Humboldt. Durante suas viagens, foi um dos responsáveis pelo método sistêmico de observação, coleta e tratamento de dados para a produção de mapas, estabelecendo, de certa maneira, padrões para a época. Humboldt também fez diversas medições de altura e distância nos continentes, sendo um exemplo durante a escalada do monte Chimborazo. Assim, ele deu base a diversos mapas do século XVIII.

Na unidade 3, "Geologia e geomorfologia", Humboldt pode ser identificado em três subtemas, sendo eles: Estrutura interna da Terra, Deriva Continental e tectônica de placas e Formação e conservação de solos. Como já apontado anteriormente, Humboldt começou sua vida lidando diretamente com o solo. Durante o período como inspetor de minas ele estudou e compreendeu grande parte dos minerais e a relação de formação entre eles. Mais tarde, apontou e descobriu diamantes na Rússia e relacionou a produção de um mineral a outro como uma interligação do solo. Também foi o primeiro cientista a propor o movimento dos continentes e das placas tectônicas, sedo esse estudo responsável por fomentar a teoria da Deriva Continental. Também discutiu os impactos da agricultura no solo e no desmatamento durante sua passagem pelas colônias americanas, e foi um dos primeiros cientistas a pontar os danos que a agricultura traz ao solo.

Por fim, na unidade 4, "Recursos hídricos e energéticos", Humboldt se aplica nos subtópicos: Ciclo Hidrológico e ação antrópica e Apropriação dos recursos hídricos e a água virtual. A questão dos rios e da água sempre foi uma preocupação primordial de Humboldt por entender a importância dela para a formação de todo o meio ambiente. Durante suas viagens pela América, concluiu, por meio de análises e entrevistas com os nativos, como o desmatamento das matas ciliares e a transposição de rios para irrigação contribuíam para a seca de grandes cursos hídricos. Dessa forma, foi o primeiro cientista a demonstrar que as atitudes antrópicas influenciavam o ciclo natural da água.

No $2^{\circ}$ ano são trabalhados conteúdos voltados para a geografia política e social, com temas como urbanização, divisão internacional do trabalho, ascensão do capitalismo e globalização (Quadro 2). Assuntos esses que não estão diretamente ligadas as temáticas trabalhadas por Humboldt, porém isso não significa que ele não tenha contribuído para tais. É possível observar influências, por exemplo, nas unidades 1 e 4.

Quadro 2. Conteúdo Programático de Geografia do $2^{\circ}$ ano do CEFET-MG.

\begin{tabular}{|c|c|}
\hline \multicolumn{2}{|r|}{ Conteúdo Programático $-2^{\circ}$} \\
\hline \multicolumn{2}{|r|}{$\mathbf{1}^{\circ}$ Bimestre } \\
\hline \multirow{7}{*}{ Unidade 1} & Capitalismo e globalização \\
\hline & 1.1 - Fases do capitalismo. \\
\hline & 1.2 - Evolução da Divisão Internacional do Trabalho. \\
\hline & 1.3 - Os setores econômicos. \\
\hline & 1.4 - Globalização e as redes de transporte. \\
\hline & 1.5 - As redes de comunicação, fluxos de informações e seus impactos. \\
\hline & 1.6 - Integração econômica e os blocos econômicos. \\
\hline
\end{tabular}




\begin{tabular}{|c|c|}
\hline \multicolumn{2}{|r|}{$2^{\circ}$ Bimestre } \\
\hline Unidade 2 & $\begin{array}{l}\text { Organização do espaço industrial e agrário } \\
\text { 2.1 - Síntese das revoluções industriais. } \\
\text { 2.2 - Tipos de indústrias. } \\
\text { 2.3 - Os fatores locacionais. } \\
\text { 2.4 - Organização do espaço industrial mundial e do Brasil (países de industrialização clássica } \\
\text { e tardia). } \\
\text { 3.1 - Síntese das revoluções da agropecuária (Revolução Agrícola, Revolução Verde, } \\
\text { Biotecnologia e Sistemas alternativos). } \\
\text { 3.2 - Organização do espaço agropecuário mundial e do Brasil (sistemas e modelos } \\
\text { agropecuários). } \\
\text { 3.3 - Questão agrária brasileira (estrutura fundiária, relações de trabalho, conflitos). }\end{array}$ \\
\hline \multicolumn{2}{|r|}{$3^{\circ}$ Bimestre } \\
\hline Unidade 3 & $\begin{array}{l}\text { Geografia da população e urbana } \\
4.1 \text { - Dinâmica demográfica mundial e do Brasil (Conceitos, indicadores, teorias } \\
\text { demográficas, transição demográfica, estrutura da população e mercado de trabalho). } \\
\text { 4.2 - Migrações no Brasil e no mundo (migrações internas e internacionais). } \\
5.1 \text { - Histórico da urbanização mundial e do Brasil. } \\
\text { 5.2 - Redes, hierarquia e aglomerações urbanas (cidade e município, metrópole, conurbação, } \\
\text { região metropolitana, macrometrópole, megalópole e cidade global). } \\
5.3 \text { - Problemas socioambientais urbanos. }\end{array}$ \\
\hline \multicolumn{2}{|r|}{$4^{0}$ Bimestre } \\
\hline Unidade 4 & $\begin{array}{l}\text { Geopolítica das relações de poder } \\
6.1 \text { - Organização política do espaço (nação, Estado-nação, fronteira, limite e espaço público). } \\
6.2 \text { - Tensões e conflitos (terrorismo; tipos de conflitos: guerra civil, separatismo, guerra entre } \\
\text { Estados e incorporação territorial). }\end{array}$ \\
\hline
\end{tabular}

Fonte: Autores.

Apesar de ser considerado um naturalista, Humboldt nunca se prendeu a uma só área da ciência. Ele dominou diferentes áreas, formando ideias essenciais, inclusive, para a estruturação da sociedade atual. Em suas viagens criticou drasticamente o modelo de sistema colonial, apontando desde o desmatamento até a falta de humanidade no tratamento com os nativos, o que pode ser tratado na unidade 1. Humboldt nunca concordou com a escravidão e a forma de trabalho utilizada nas colônias e sempre deixou claro em suas obras os problemas ocorridos nas Américas e como isso criava um ciclo vicioso de problemas. Por meio de livros, cartas e palestras Humboldt destacou, mesmo que de maneira não intencional, pontos importantíssimos que contribuiriam para a evolução da divisão internacional do trabalho.

Além das críticas, as práticas e formas como Humboldt estruturava seus projetos contribuíram muito para a sociedade. Ele foi conseguiu reunir e conectar cientistas do mundo todo através de suas cartas e eventos científicos. A França, na época como berço da ciência, transbordava informações e conhecimentos e dali o conhecimento era transpassado para o resto do mundo. Assim, teria início, também, o desenvolvimento de uma rede de troca de informações e conhecimentos científicos.

No que diz respeito ao tema Tensões e conflitos, da unidade 4, Humbold teve uma forte influência na incorporação/expansão territorial dos EUA, especialmente rumo ao oeste. Durante sua passagem pelo país, catalogou e estudou grande parte do território, além da região da fronteira com o México, descrevendo a vegetação, o relevo, a fauna e até aspectos socioeconômicos. Ao encontrar com Thomas Jefferson, que foi um grande amigo de Humboldt e presidente dos EUA, forneceu grande parte de seus estudos, explicou suas análises e opinou sobre territórios até então inexplorados. Esse marco foi essencial para a incorporação do território americano no eixo oeste e também no domínio americano sobre o México. 


\section{Considerações}

A partir das análises feitas durante o desenvolvimento do projeto podem ser elencadas algumas considerações. É inegável que Humboldt foi um nome importantíssimo para a ciência, suas atribuições não se perderam no século XVIII, se fazem necessárias e presentes até hoje. Ele não foi somente um naturalista, como mostrado, trabalhou em diversas áreas de conhecimento, e em todas elas trouxe agregou conteúdo. A sistematização da natureza como uma rede de interligações e as primeiras ideias geográficas foram aprimoradas por ele dando sequência para diversos estudos futuros, e até mesmo para a formação da disciplina acadêmica Geografia. Humboldt criticou, pioneiramente, a interferência humana sobre o meio ambiente e explicou como os seres humanos são os destruidores primários dos recursos naturais. Muito dos assuntos introduzidos por Humboldt foram reconhecidos na sociedade atual, como a ligação da natureza e a interferência humana direta com a natureza, que hoje são assuntos considerados comuns. Talvez seja nesse ponto que Humboldt tenha perdido sua visibilidade no meio social atual. Em sua época ele foi extremamente revolucionário e postulou descobertas essenciais para a formação da sociedade. Hoje seus postulados se difundiram socialmente e seu nome não.

Outro ponto tratado no projeto é o reconhecimento de Humboldt na geografia escolar, como mostrado na análise do currículo geográfico do CEFET-MG. Humboldt está presente nas quatro Unidades ministradas no $1^{\circ}$ ano do ensino médio, desde a introdução à geografia, onde ele aparece como um dos primeiros a aplicar o pensamento sistêmico de natureza, até o uso dos recursos hídricos e energéticos, tratados na Unidade 4. Essa presença afirma mais uma vez a importância dele para a geografia como um todo. O problema é que mesmo presente em todas as unidades, nenhum deles trata definitivamente do nome de Humboldt, mais uma vez mostrando a falta de propagação do seu nome. Já no $2^{\circ}$ ano, Humboldt aparece de forma mais sutil, porém ainda presente, nas Unidades 1 e 4, tratando um pouco sobre a parte social e sua ideia de socialização e troca de informações, que foram essenciais para levar a geografia a patamares mundiais durante os séculos XVIII, e não somente aos polos científicos como França e Alemanha. Essa troca de informações foi essencial para a globalização do planeta e para o avanço incessante da sociedade e da tecnologia durante os séculos XVIII e XIX.

Sugere-se, assim, o desenvolvimento de pesquisas futuras que possam propor metodologias capazes de transpor o conhecimento acadêmico advindo das descobertas de Humboldt para o ambiente escolar. Assim, seria possível a criação de metodologias que interrelacionem os conteúdos de cada Unidade tratada no CEFET-MG, por exemplo, com cada apontamento feito, ainda no século XVIII, por Humboldt. Essa seria uma possibilidade para tornar seu nome presente no Ensino Médio e lembrado no ambiente escolar como um todo.

\section{Referências}

Amorim Filho, O. B. (1999). A evolução do pensamento geográfico e a fenomenologia. (In): Sociedade \& Natureza, Uberlândia, 11 (21 e 22): 67-87, jan./dez. Barsand, P. R., \& Barbosa, R. P. (2012). Meio ambiente: guia prático e didático. São Paulo: Érica.

Borsa, J. C. (2013). O papel da amizade ao longo do ciclo vital. (In): Psico-USF, Bragança Paulista, v. 18, n. 1, p. 161-162, jan./abril.

Bukowski, W. M., Newcomb, A. F., \& Hartup. W. W. (eds.) (1996). The company they keep: f riendship in childhood and adolescence. Cambridge, University Press, p. 1-15.

Callai, H. C. (2011). A Geografia Escolar - e os conteúdos da Geografia. (In): Revista Anekuneme, n.1, p.128-139.

Camargo, L. H. R. (2005). A ruptura do meio ambiente: conhecendo as mudanças ambientais no planeta através de uma percepção da ciência: a geografia da complexidade. Rio de Janeiro: Bertrand Brasil.

Cavalcanti, L. S. (2012). Concepções teórico-metodológicas e docência da Geografia no mundo contemporâneo. (In): O ensino de geografia na escola. Campinas, São Paulo: Papirus. P208.

Cheng, H., \& Furnham, A. (2002). Personality, peer relations, and self-confidence as predictors of happiness and loneliness. Journal of Adolescence.

Claval, P. (2002). A revolução pós-funcionalista e as concepções atuais da geografia. In: Mendonça, F.; Kozel, S. (orgs.). Elementos de Epistemologia da Geografia Contemporânea. Curitiba: Editora da UFPR, p. 11-46. 
Dantas, A.; Medeiros, T. H. L. (2008). A geografia de Humboldt e Ritter. (In): Introdução à Geografia. UFRN - Universidade Federal do Rio Grande do Norte e da UEPB - Universidade Estadual da Paraíba.

Ferreira, C. C., Simões, N. N. (1986). A Evolução do Pensamento Geográfico. Lisboa: Gradiva.

Goettems, A. A., Joia, A. L. (2016). Geografia: Leituras e Interação. $2^{\text {a }}$ ed. São Paulo: Leya.

Hartshorne, R. (1978). Propósitos e natureza da Geografia. São Paulo: Hucitec/ Edusp.

Hartup, W. W. (1996). The company they keep: friendships and their developmental significance. Child Development, 67(1),1-13.

Leff, E. (2006). Epistemologia ambiental. São Paulo: Cortez, 2006.

Limberger, L. (2006). Abordagem sistêmica e complexidade na geografia. (In): Geografia - v. 15, n. 2, jul./dez. http://www.uel.br/revistas/geografia.

Marquez, R. M (2008). Imagens da natureza. In: Hissa, C. E. V. (Org.) Saberes ambientais: desafios para o conhecimento disciplinar. Belo Horizonte: Ed. Ufmg. p. 33-45

Nascimento, F. R., Sampaio, J. L. F. (2004). Geografia física, Geossistemas e estudos integrados da paisagem. (In): Revista da Casa da Geografia de Sobral, Sobral, v. 6/7, n. 1, p. 167-179, 2004.

Neto, J. L. S. (2008). Da climatologia geográfica à geografia do clima - gênese, paradigmas e aplicações do clima como fenômeno geográfico. (In): Revista da ANPEGE, v.4, 51-72.

Sene, E.; Moreira, J. C. (2016). Geografia Geral e do Brasil: espaço geográfico e globalização. $3^{a}$ ed. São Paulo: Scipione.

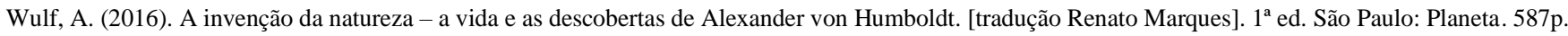

